\title{
BABESIOSIS SURVEY OF VOLES OF GRAND TETON NATIONAL PARK
}
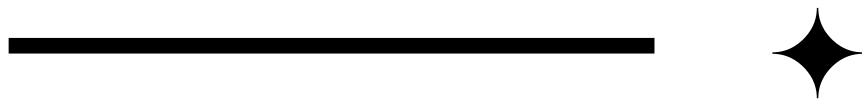

\section{KEVIN L. BARTON $\uparrow$ DEPARTMENT OF BIOLOGY $\uparrow$ UNIVERSITY OF NEBRASKA-OMAHA}

\section{$\uparrow \quad$ PURPOSE OF THE STUDY}

First described in 1885 by Viktor Babes, babesiosis was the first known arthropod vectorborne disease and the general term for the malarialike infection due to protozoan parasites of the family Babesiidae of which there are on the order of 100 known species of worldwide distribution (CDC, Hunfeld et al. 2008). The overarching objective of this study is to examine the phylogenetic relatedness of the endemic strain(s) of Babesia microti isolated from voles (Microtus montanus, M. pennsylvanicus) in the Grand Teton National Park to previously described babesia species/strains. In the United States the rodent parasite $B$. microti is the etiological agent of babesiosis in areas of endemicity with the primary reservoir often described as the white-footed mouse (Peromyscus leucopus) and borne by the arthropod vector the black-legged tick (Ixodes scapularis) (Persing et al. 1992, Mitchell et al. 1996) The primary reservoir within the Grand Teton National Park region has been shown to be the meadow vole (Microtus pennsylvanicus) and the montane vole (Microtus montanus) (Watkins et al. 1991, Peck 1998) It is these reservoir host animals which the present research proposes to investigate. To this end, the research aspects specific to our IACUC proposal are to obtain blood samples for subsequent genotyping of $B$. microti samples for comparison to those previously isolated from wild populations of voles from the Grand Teton National Park region (Peck 1998). This research generally involves comparing DNA sequences from isolates to those of previously described strains focusing on the B-tubulin genes. This was selected to give a more particular phylogeny than was possible by previously employed methods such as immunoassay, which lacks sensitivity and suffers cross-reactivity, and 16sribosomal DNA of the past decade, which lacks specificity relative to the less highly-conserved Btubulin. These samples will be genotyped by sequencing and comparison against the relatively more recent Genbank B-tubulin sequence data submissions for $B$. microti variants.

Whereas the precise identification of a host organism is an essential element of the taxonomic recognition of a potentially new species of parasite, exact identification and preservation of the host specimen from which a parasite specimen is collected is also important. The voucher specimens of voles thus obtained, upon return to Nebraska, will be appropriately prepared and placed in the University of Nebraska at Lincoln collection.

\section{$\downarrow \quad$ Potential VAlue OF The Study}

The value of this research in the specific elaboration of the regional distinction in B. Microti strain from voles lies primarily in the observation that the species-specificity and virulence, including human cases of the disease, appears to be highly dependent on slight variations in closely related babesia strains. Babesiosis in general is a worldwide disease of considerable economic consequence and an increasingly recognized cause of morbidity and mortality in humans. Some areas of the northeast and northern Midwest states have shown positive antibody titers to $B$. microti by up to $10 \%$ of the residents, apparently from sub-clinical infection (Krause et al. 2003) so the true incidence has only begun to be explored by epidemiologists. Human to human Babesiosis via blood-transfusion and maternal-fetal transmission has also been documented in a number of cases and therefore now poses an additional risk to individuals receiving blood products who by reason of other debility are 
more likely susceptible to serious infection. For these reasons, babesiosis is now recognized as an emerging zoonosis in the United States, most specifically among splenectomized or otherwise immune-suppressed persons and therefore of some public health concern as well (Saito-Ito et al. 2000, Shuster 2002) and a reportable infectious disease in some jurisdictions. The specific identification of host/parasite strain in particularly relation to increased human encroachment of natural habitat of voles and other rodents as a reservoir species will ultimately aid in assessing the breadth and likelihood of cross to other species, including humans, in endemic areas such as GTNP.

The primary objective of the present research is to specify the natural endemic strain of $B$. microti within these vole populations by the most specific current molecular genetics techniques. $B$. microti is an obligate intraerythrocytic protozoan parasite and cannot readily be cultured outside of a suitable host animal (Valois-Crus 2006, Bautista and Kreier 1979) thus necessitating larger blood-sample volumes than might be otherwise possible if small sample inocula could be cultured in-vitro. Natural infections in these populations typically manifest quite low parasitemias on the order of .1 to $2 \%$ (Watkins et all 1991). Inasmuch as this is the study of a blood infecting organism, sufficient sample volume to provide enough $B$. microti DNA to reliably perform multiple experimental analyses would, unfortunately, render the animals unfit to return to the wild.

The current research follows and expands upon studies conducted for several years, 1987 to 1990 (Watkins et.al. 1991) in Grand Teton National. Park describing splenomegaly and reticulocytosis of voles and other rodents determined by microscopical detection of presumed $B$. microti piroplasms as the causative agent and Peck (1998) by analysis of ribosomal 16s-like subunit DNA sequence therefore necessitating study of the identical species to yield a meaningful comparison.

\section{$\uparrow \quad$ RESEARCH DESIGN}

The essential design simply involves collection of a statistically useful number of wild voles $(n=26)$ calculated to reasonably ensure that parasitized animals will be included in the survey. Relevant literature regarding infection prevalence in host populations is somewhat limited although typical reported infection rates range from approximately 16 to $35 \%$ (Watkins et.al.), with values dependent upon location, season, predator populations, host population density and other factors.

In order to ensure sample size adequate to provide infected animals this is taken as a binomial distribution problem based on the lower reported infection incidence of $16 \%$. As such, this means that in any sample size (n) the number of animals expected to be free of infection would be $(1-.16)^{\mathrm{n}}$ To attain a $99 \%$ probability of the sample containing at least one infected animal:

Setting prob. of $<1$ infected animal in sample $=.01$ so let $.01=(.84)^{\mathrm{n}}$ where $\mathrm{n}=$ sample size.

So, $99 \%$ confidence level based on lower incidence estimate:

$$
\mathrm{n}=\log (.01) / \log (.84)=-2.00 /-.076 \text { or } \mathrm{n}=
$$
26 animals minimum sample size.

These will be assayed for infection of $B$. microti parasites by blood-smear examination and DNA amplification utilizing the Polymerase Chain Reaction technique and sequencing the parasite Btubulin gene so that elucidation of the particular infectious strain of this organism within this previously studied vole population may be accomplished. The genomic sequence data will be analyzed to construct the phylogeny of this strain of $B$. microti as the ultimate goal of the research.

\section{$\uparrow \quad$ RESULTS}

A first field collection near the Grand Teton National Park during August of 2011 was limited, but successful. In 2011, unusually poor weather, with a very late spring and flooding, resulted in exceptionally poor habitat conditions that affected both small-mammal and tick populations. This limited the size and number of animals obtained, and these stressors are also presumably responsible for the observed high trap mortality. Despite these difficulties, some infected animals were collected, although not in numbers that would support robust statistical analysis. DNA from blood of these animals (containing the target babesial DNA) has been prepared, and these animals have been delivered to the Nebraska State Museum as voucher specimens for preservation and identification. The parasite genomic data are not yet available as this portion of the study is still underway. 
Table 1. Spreadsheet summarizing the 2011 collection data.

MANDATORY CODING

OPTIONAL

\begin{tabular}{|c|c|c|c|c|c|c|c|c|c|c|c|c|c|c|c|c|}
\hline \multicolumn{17}{|c|}{ CODIN } \\
\hline 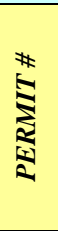 & $\frac{v}{s}$ & 矛 & 悹 & 式 & 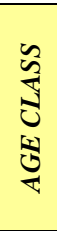 & $\overrightarrow{\mathrm{a}}$ & 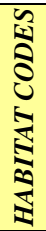 & 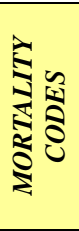 & 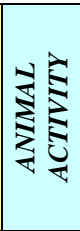 & 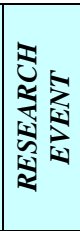 & 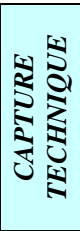 & 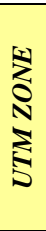 & $\begin{array}{l}0 \\
\vdots \\
\vdots \\
\vdots \\
\vdots \\
\vdots \\
\vdots\end{array}$ & 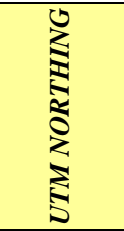 & $\frac{\mathfrak{s}}{\mathfrak{s}}$ & 疍 \\
\hline 816 & $8 / 10 / 2011$ & 887 & F & & A & 1 & 6 & 0 & 5 & 5 & 2 & 12 & 524786 & 4877686 & NAD83 & \\
\hline 816 & $8 / 10 / 2011$ & 887 & $\mathrm{U}$ & & $\mathrm{J}$ & 1 & 6 & 0 & 5 & 5 & 2 & 12 & 524786 & 4877686 & NAD83 & \\
\hline 816 & $8 / 10 / 2011$ & 887 & $\mathrm{U}$ & & $\mathrm{J}$ & 1 & 7 & 0 & 5 & 5 & 2 & 12 & 524786 & 4877686 & NAD83 & \\
\hline 816 & $8 / 10 / 2011$ & 896 & F & & $\mathrm{A}$ & 1 & 7 & 0 & 5 & 5 & 2 & 12 & 527273 & 4880501 & NAD83 & released \\
\hline 816 & $8 / 10 / 2011$ & 887 & $\mathrm{U}$ & & $\mathrm{J}$ & 3 & 7 & 0 & 5 & 5 & 2 & 12 & 527273 & 4880501 & NAD83 & \\
\hline 816 & $8 / 10 / 2011$ & 887 & $\mathrm{U}$ & & $\mathrm{J}$ & 1 & 7 & 0 & 5 & 5 & 2 & 12 & 525876 & 4883860 & NAD83 & \\
\hline 816 & $8 / 11 / 2011$ & 887 & $\mathrm{U}$ & & $\mathrm{J}$ & 2 & 6 & 0 & 5 & 5 & 2 & 12 & 524786 & 4877686 & NAD83 & \\
\hline 816 & $8 / 11 / 2011$ & 887 & $\mathrm{U}$ & & $\mathrm{J}$ & 4 & 7 & 0 & 5 & 5 & 2 & 12 & 527273 & 4880501 & NAD83 & \\
\hline 816 & $8 / 12 / 2012$ & 896 & $\mathrm{~F}$ & & A & 1 & 6 & 0 & 5 & 5 & 2 & 12 & 524786 & 4877686 & NAD83 & released \\
\hline 816 & $8 / 12 / 2012$ & 887 & $\mathrm{U}$ & & A & 1 & 7 & 0 & 5 & 5 & 2 & 12 & 527273 & 4880501 & NAD83 & \\
\hline 816 & $8 / 13 / 2012$ & 887 & $\mathrm{U}$ & & A & 1 & 6 & 0 & 5 & 5 & 2 & 12 & 524786 & 4877686 & NAD83 & \\
\hline 816 & $8 / 13 / 2012$ & 887 & $\mathrm{U}$ & & $\mathrm{J}$ & 6 & 7 & 0 & 5 & 5 & 2 & 12 & 527273 & 4880501 & NAD83 & \\
\hline
\end{tabular}

$887=$ montane vole

$896=$ Western jumping mouse

This study was performed with the approval of the UNMC/UNO IACUC, protocol \#11-048-06EP.

The accompanying Excel spreadsheet summarizes the 2011 collection data in the format recognized by the Wyoming Game and Fish Department under state scientific collecting permit \#33-816 (Table 1.)

\section{LITERATURE CITED}

Bautista CR, Kreier JP. 1979. Effect of immune serum on the growth of Babesia microti in hamster erythrocytes in short-term culture. Infection and Immunity. 197:470-472.

Centers for Disease Control, Laboratory identification of parasites of public health concern; Babesiosis http://www.dpd.cdc. gov/dpdx/HTML/ Babesiosis.htm

Hunfeld KP, Hildebrandt A, Gray JS. 2008. Babesiosis: Recent insights into an ancient disease. International Journal of Parasitology 38.11:1219-37. doi:10.1016/ j.ijpara.2008.03.001.PMID 18440005.
Krause PJ, et al. 2003. Increasing health burden of human Babesiosis in endemic sites. American Journal of Tropical Hygiene 68:431-436.

Mitchell PD, Reed KD, Hofkes KM. 1996. Immonoseroligic evidence of co-infection with Borrelea bungdrrferi, Babesia microti, and human granulocytic Erlichia species in residents of Wisconsin and Minnesota. Journal of Clinical Microbiology. 34:724727.

Persing DH, Mathiesen D, Marshall WF, Telford SF, Spielman A, Thomford JW, Conrad P. 1992. Detection of Babesia microti by polymerase chain reaction. Journal of Clinical Microbiology. 30:2097-2103.

Peck, Y. 1998. The phylogenetic characterization of Babesia microti in Grand Teton National Park and its relationship to related species. Masters degree thesis, Univ. of Nebraska, Omaha, Department of Biology

Saito-Ito A, Tsuji M, Wei Q, He S, Matsui T, Kohsaki M, Aral S, Kamiyama T, Hioki K, Ishihara C. 2000. Transfusion acquired autochthonous human Babesiosis in Japan: 
Isolation of Babesia microti-like parasites with hu-RBC-SCID mice. Journal of Clinical Microbiology. 4511-4516.

Shuster FL. 2002. Cultivation of Babesia and Babesia-like blood parasites: Agents of an emerging zoonotic disease. Journal of Clinical. Microbiology. Review. 15:365-373 (doi:10.1128/CMR.15.3.365-373.2002).

Valois-Cruz F, Loa C, Mordechai E, Tilton RC, Adelson ME. 2006. Experiences on the development of dontinuous In Vitro culture for Babesia microti. 106th American Society of Microbiology General Meeting (Abstract only).

Watkins RA, Moshier SE, O’Dell WD, Pinter AJ. 1991. Splenomegaly and reticulocytosis caused by Babesia microti infections in natural populations of the montane vole, Microtus montanus. Journal of Protozoology 38:573-576. 